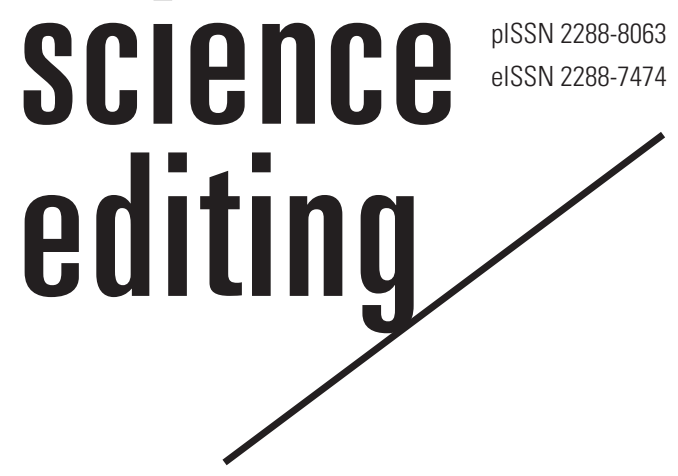

\title{
Why and how do we keep editing local medical journals in an era of information overload?
}

\author{
Viera Wardhani', Sam Mathew², Jeong-Wook Seo ${ }^{3}$, Komang G. Wiryawan', \\ Vivi Setiawaty ${ }^{5}$, Burmaajav Badrakh ${ }^{6}$
}

${ }^{1}$ Universitas Brawijaya, Malang, Indonesia; ${ }^{2}$ Glaxo SmithKline Pharmaceuticals, Mumbai, India; ${ }^{3}$ Seoul National University College of Medicine, Seoul, Korea; ${ }^{4}$ Bogor Agricultural University, Bogor, Indonesia; ${ }^{5}$ National Institute of Health Research and Development, Ministry of Health, Jakarta, Indonesia; ${ }^{6}$ Mongolian Academy of Medical Science, Ulaanbaatar, Mongolia

\section{Introduction}

The joint convention of the Asia Pacific Association of Medical Journal Editors (APAME) and the fifth Asian Science Editors' Conference and Workshop 2018 was held on July 18-19, 2018 at the IPB International Convention Center, Bogor, Indonesia [1]. This was the first joint convention between these two well-known journal editors' associations in this region, APAME [2] and the Council of Asian Science Editors [3]. According to Komang G. Wiryawan, the chairman of the local organizing committee, a total of 254 participants from 21 countries attended the convention. There were 39 lectures and 6 poster presentations.

Two specific sessions that highlighted the geographic and social characteristics of countries in this region deserve special mention. One of these sessions discussed the status of scholarly journals from the following Association of Southeast Asian Nations countries: Vietnam, Singapore, Indonesia, Malaysia, Philippines, Thailand, and Myanmar. The other session involved group discussions among journal editors and researchers representing journals from different subject areas: agricultural and natural science journals, engineering journals, medical and health journals, and journals on social sciences and other disciplines. Journal editors and researchers specializing in the above subject areas were assigned to their respective discussion groups.

The overall theme for this group discussion was 'How to develop science journals in Asia?' The medical and health journal group specifically discussed 2 vital questions: why and how are we editing medical and health journals? Herein, we summarize the issues and solutions discussed by the participants in the medical and health journal group.

Fig. 1 presents the participants of the medical and health journal group, which comprised 35 journal editors and/or researchers from 8 countries. Twenty-five were from Indonesia and the remaining participants were from Korea, Japan, Mongolia, Philippines, India, Laos, and Malaysia. 


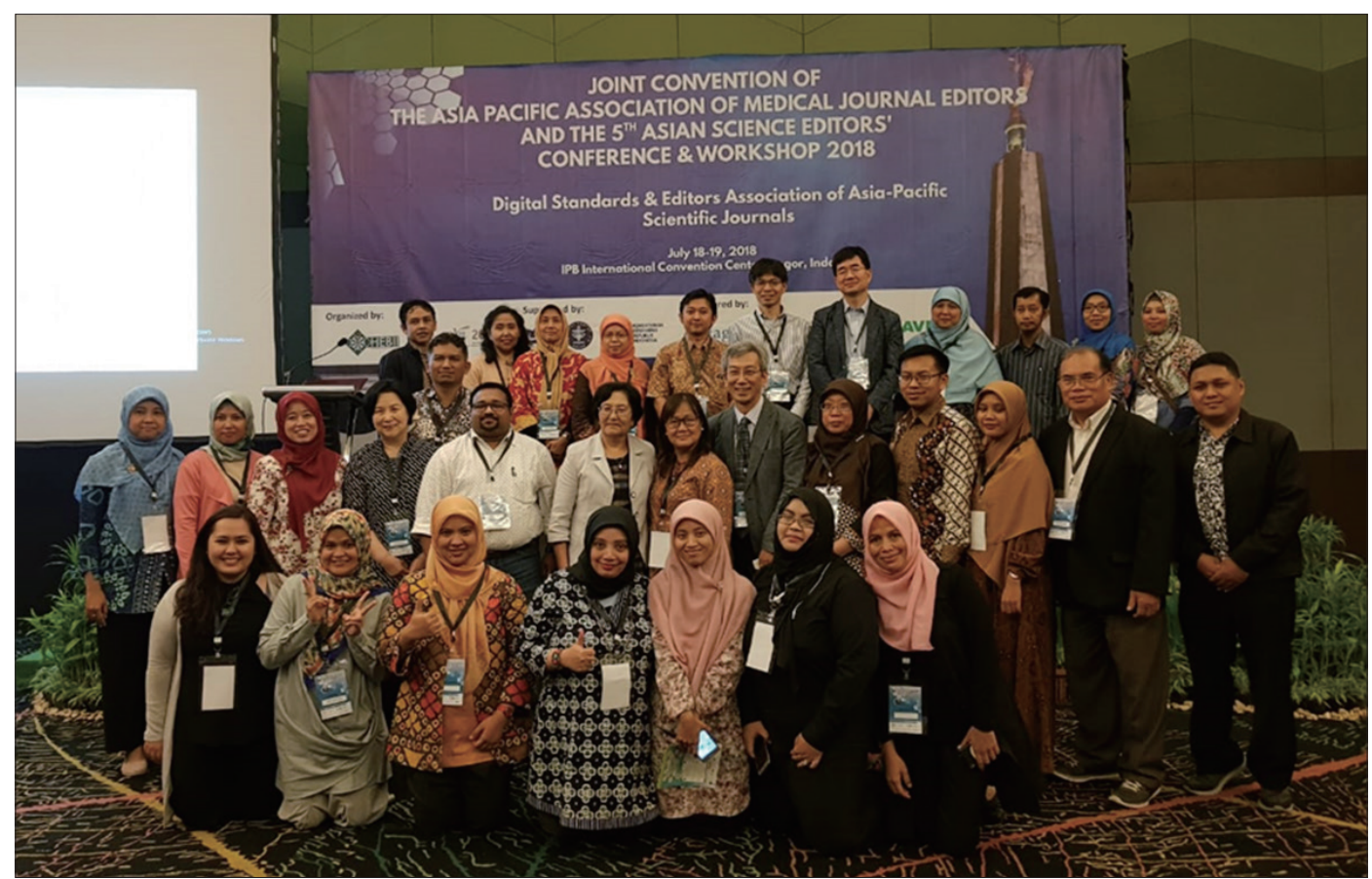

Fig. 1. Participants from medical and health journals' group discussion session of the the Joint Convention of the Asia Pacific Association of Medical Journal Editors and the 5th Asian Science Editors' Conference and Workshop 2018 on July 18-19, 2018 at the IPB International Convention Center, Bogor, Indonesia.

\section{Critical Issues in Scholarly Publishing}

The journals represented by the participants had various specific issues. Therefore, it was important for the participants to identify critical common issues that their journals faced. The majority of the participants were concerned about worryingly low numbers of submissions to their journals. Most local journals are sponsored and published by a local institution or society, and members of that institution or the society are generally expected to submit their research for publication in the sponsored journal. The number of articles produced by members of the organization clearly depends on the size and capacity of the organization. However, even if there are relatively many members of those organizations who actively publish their research, or if the organizations produce a relatively high number of scholarly articles, the number of articles submitted to the journal published by the institution or society can still be limited.

With increasing pressure and incentives to significantly improve the international visibility of papers, authors often submit their articles to international journals published in foreign countries, making it difficult for local journals to attract quality submissions. As a result, some local journals do not receive enough submissions to publish issues regularly, which in turn jeopardizes journals' status, indexing activities, and image. The participants felt that this was a serious threat to the value and sustainability of such local journals.

The participants also raised concerns about the poor editing standards adopted by local journals and the lack of financial and human resources. It was also mentioned that independent or commercial publishers are only interested in supporting journals that are heavily dependent on a local institution or government for support.

While coping with these challenges, professionals involved in scholarly publishing are liable to ask fundamental questions about why we continue to confront these challenges. The participants unanimously identified the fundamental issue as a surplus of journals. The whole issue, however, is too complicated to explain in a short sentence. The current challenges started with the introduction of digital technology in writing and publishing $[4,5]$. Clearly, digital technology is beneficial for authors in that it enables them to produce more articles. Publishers also receive benefits through online publishing and e-journals. As digital technology emerged, publishers with sophisticated technology were able to produce better journals and publish more. However, the number of journal titles increased faster than the number of articles produced. Major international journals received more manuscript submissions, whereas journals published in less-served countries experienced a rapid drop in the number of submitted articles. In fact, commercial publishers founded many new journals that became black holes for manuscripts. After the introduction of 
science editing /

the open access concept, subscription journals were no longer expected to be major players. However, the surplus of new journals founded by commercial publishers has caused challenges for local journals. If local journals disappear, commercial open access journals will prevail and may obtain a monopoly [6]. In such a situation, the authors of scholarly articles may be forced to pay more money to publish their research than to actually conduct it. Therefore, it is important for local researchers to maintain their local journals as a platform for scholarly communication and to keep them as a gateway for global interactions.

The publishers, governmental organizations, and universities that sponsor local journals should encourage editors to improve the editing standards of these journals. Publishers should launch initiatives to support local journals that lack financial support and human resources.

\section{Why Do We Publish Local Journals?}

It is not easy to explain why we still publish local journals. It was evident in this session that the majority of editors of local journals are doubtful whether they will be able to continue publishing for more than 10 years without interruption. However, the participants identified many reasons to support the publication of local journals. Local journals are an important medium for teaching faculty to guarantee that their research is published quickly to meet requirements for promotion in faculty positions. Students and young researchers also had a similar opinion that local journals are needed for their early career development. They also admitted that it might be possible to get rid of local journals, but warned that the void will be replaced by predatory journals or other commercial journals. In either scenario, publishing in such journals may not be affordable for local researchers from developing or underdeveloped countries. Therefore, it is not appropriate to give in to the challenges of publishing local journals, since ceasing to publish local journals would not help solve these major issues in research and publishing.

\section{How Can We Improve Our Local Journals?}

If institutes or professional societies that publish a local journal do not launch initiatives to improve the quality of the journal, its editors should assume the responsibility to improve the editorial standards of the journal or they should find alternatives.

The participants identified 5 major approaches for improving local journals: (1) help researchers publish more actively; (2) encourage authors to submit their papers to the local journal; (3) strategically invite productive scholars to the govern- ing and editorial boards; (4) diversify the document types; and (5) adopt advanced publishing strategies

It has been observed that some researchers are very good at publishing their research findings, while others are not. Editors of local journals should focus on active researchers who usually do not publish their research findings and encourage them to write up their research outcomes. If researchers experience difficulties in drafting a research paper or in collating and contextualizing information, the editor or editorial members of the journal can mentor them or direct the researchers to seek professional support from experts. It is important for the editors to make such researchers aware of the principle 'publish or perish.' Editors should encourage authors to develop conference abstracts into full-length research papers whenever possible.

In certain cases, there are legitimate reasons for potential authors to avoid publishing in local journals, including the quality of editorial work, editorial process, and response time. Editors should try to improve the editorial standards of the journal by having professional language experts edit the manuscripts and by setting up a transparent editorial process with defined timelines and clear communication.

Another approach to attract submissions is to invite active authors and reputed researchers to the governing and editorial boards. Editors should request quality submissions from these editorial members periodically.

In addition to publishing conventional research documents, the editorial team should implement innovative document types and diversify the scope of the dissemination of knowledge. These diverse document types will break away from the monotonous nature of publications. Such documents include, but are not restricted to, voices from the field, pictorial essays, and meeting reports. Editorial notes can be used more widely for research papers to provide a brief description of the context of the research to the reader, thereby enhancing the reader's enthusiasm. Journals should also encourage letters to the editor from seasoned researchers and support healthy discussions and deliberations in the space provided by the journal.

It is also a good idea to leverage the scope of social media and advances in information technology to attract authors and readers. Busy researchers and authors will benefit from modular information produced in an effective and engaging way.

Adopting best practices in electronic publishing can enhance the readership of journals. Local journals should also try to deploy new publishing technologies, which will promote the indexation of articles in reputable databases, help in searching for and identifying published papers and authors, and assist in the archival and retrieval of published papers. Depending on the financial resources of the journal, in addition to the customary PDF format, XML, HTML and multi- 
media formats can also be implemented to attract authors and readers.

\section{Participating in Coalitions of Journals}

Although an editor can improve the quality of a journal in various innovative ways, a single stand-alone local journal is always isolated to some degree. Therefore, it is always advisable to be part of coalition of journals to improve visibility. Herein, the concepts of coalitions and alliances are considered from two perspectives: indexing databases, wherein journals are selected based on predefined criteria, and groups of journals published by a common publisher.

Although Web of Science, Medline, and Scopus are indexing databases for articles from selected journals, they also function as an alliance of standard journals. Being indexed in such prominent databases improves a journal's visibility and confirms its quality and credibility.

The Western Pacific Region Index Medicus [7,8], Index Medicus South East Asian Region [9], Association of Southeast Asian Nations Citation Index [10], and Directory of Open Access Journals [8] are essentially indexing databases, but in effect they function as coalitions of journals. Science Direct and SpringerLink are journal groups supported by commercial publishers. E-Science Central and APAMED Central are similar to these digital journal groups, but without any link to commercial publishers. The Indonesian Association of Science Journal Editors (IASJE) [11,12], Indonesia Association of Medical and Health Journal Editors, the Korean Council of Science Editors [13], the Korean Association of Medical Journal Editors [14]), and Mongolian Association of Medical Journal Editor are examples of loosely bound journal alliances, and the SINTA (Science and Technology Index) [15] for IASJE/Himpunan Editor Berkala Ilmiah Indonesia [12] and KoreaMed for Korean Association of Medical Journal Editors function as strong facilitators of those alliances. Council of Asian Science Editors [3] and APAME [2] are international alliances led by editors, rather than by publishers or journals themselves. There is a case of cooperation in Indonesia. With the increasing use of social media, the members of the Indonesian Association of Medical and Health Journal Editors have created a group communication channel for editors of health journals through WhatsApp, thereby facilitating easy communication. This group is now referred to as Forum Jurnal Kesehatan (the Health Journal Forum). Through this WhatsApp group, members share information about editing problems, the lack of good articles, and seek reviewers with expertise specific to the topics of various articles.

How can these alliances or coalitions help? They can support their member journals and editors by conducting educa- tional training and conference activities to improve journal formatting and editorial practices. Searchable databases operated by these alliances are highly advantageous. It is crucial for journals to produce high-quality metadata sets and aggregates of significant size and quality. These aggregated data sets can be further used by international aggregators, such as Google Scholar, Naver Academic, and Microsoft Academic.

\section{Constructive Restructuring of Journals}

Strategic and constructive restructuring of journals is a challenging task for editors and publishers. In this context, restructuring refers to merging different journals to create a single sustainable journal. Restructuring should be performed in multiple steps. The first step is to improve the quality of the journal with the help of alliances and coalitions. The next step is to identify partner journals with which the journal can be merged. This step, however, depends closely on the opinion of all stakeholders, including authors, readers, editors, publishers, governmental bodies, and institutions. The merger may be intranational or international, and it may be among journals with the same scope or focusing on the same scientific discipline, but it is advisable to make the scope relatively broad in order to benefit more readers and authors. When comparing the two likely scenarios for a journal experiencing major challenges to the point that it is non-sustainable-discontinuing it or creating a larger journal by merging it with suitable partner journals - the latter option is more advantageous to scholarly publishing as a whole.

Indonesia, for example, is a large country with tremendous resources for scholarly publication. It is the country in Asia with the highest number of journals (365 in 2017) indexed in Directory of Open Access Journals [5], and it has the fifth largest number of institutional repositories. However, only 30 Indonesian journals are indexed in Scopus [16]. This discrepancy can be attributed to the presence of many small journals in Indonesia. Although this is clearly the authors' opinion, we nonetheless suggest that these small journals should be merged to create larger journals that would have a wider impact. There are 51,158 journals indexed in the national database, whereas only 7,817 journals are accredited [17]. The first challenge in merging journals might stem from concerns about losing institutional identification and reducing the opportunities for local authors to publish their papers. However, there are several good examples of older local journals being restructured to form international journals $[18,19]$. One example was told by Prof. Komang G. Wiryawan. "The government of Indonesia and IASJE have tried to improve journal quality and to have more journals indexed in Scopus or Web of Science. Based on my experiences as the chief editor of 


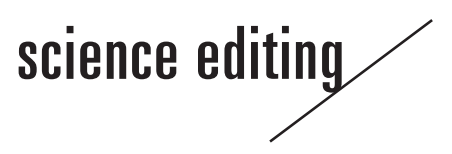

Tropical Animal Science Journal (previous name: Media Peternakan), once our journal was indexed in Scopus in 2016, the number of submitted manuscripts increased substantially, to the point that the rejection rate increased to more than $60 \%$. Some of the submitted manuscripts are still of poor quality, but we saw rapid progress in the quality of the submitted manuscripts. A short-term goal of IASJE could be to improve researchers' skills in writing scientific publications."

\section{Conclusion}

The sustainability of local journals is the need of the hour. Local journals are the only affordable medium for early-career researchers and researchers from developing and underdeveloped countries to disseminate their findings. This group discussion effectively identified and proposed 5 basic strategies to improve the quality of local journals, and emphasized the importance of participating in alliances/coalitions and constructive restructuring of journals.

\section{Conflict of Interest}

No potential conflict of interest relevant to this article was reported.

\section{References}

1. Council of Asian Science Editors. Joint Convention of the Asia Pacific Association of Medical Journal Editors and the 5th Asian Science Editors Conference \& Workshop 2018 [Internet]. Seoul: Council of Asian Science Editors; 2018 [cited 2018 Aug 1]. Available from: https://www.asianeditor.org/event/2018/

2. Asia Pacific Association of Medical Journal Editors [Internet]. Manila: Asia Pacific Association of Medical Journal Editors [cited 2018 Aug 6]. Available from: http://apame.link

3. Council of Asian Science Editors [Internet]. Seoul: Council of Asian Science Editors [cited 2018 Aug]. Available from: https://www.asianeditor.org

4. Salager-Meyer F. Scientific publishing in developing countries: challenges for the future. J Engl Acad Purp 2008;7: 121-32. https://doi.org/10.1016/j.jeap.2008.03.009

5. Seo JW, Chung H, Seo TS, et al. Equality, equity, and reality of open access on scholarly information. Sci Ed 2017;4: 58-69. https://doi.org/10.6087/kcse.97

6. Tennant JP, Waldner F, Jacques DC, Masuzzo P, Collister LB, Hartgerink $\mathrm{CH}$. The academic, economic and societal impacts of Open Access: an evidence-based review. F1000Re- search 2016;5:632. https://doi.org/10.12688/f1000research. 8460.1

7. Seo JW, Park JH, Kim H, Park JY, Park MJ, Kim HY. Korean medical libraries and professional associations: changing services and roles. Health Inf Libr J 2008;25:142-9. https:// doi.org/10.1111/j.1471-1842.2008.00776.x

8. Directory of Open Access Journals. DOAJ search [Internet]. [place unknow]: Directory of Open Access Journals [cited 2018 Aug 1]. Available from: http://doaj.org/search

9. World Health Organization. Index Medicus for the SouthEast Asian Region [Internet]. Geneva: World Health Organization [cited 2018 Aug 6]. Available from: http://www. who.int/library/databases/searo/en/

10. Asean Citation Index. Journal selection criteria [Internet]. Bangkok: Asean Citation Index [cited 2018 Aug 6]. Available from: http://www.asean-cites.org/index.php? $r=$ contents\%2Findex\&id=10

11. Wiryawan KG. The current status of science journals in Indonesia. Sci Ed 2014;1:71-5. https://doi.org/10.6087/kcse.2014.1.71

12. Himpunan Editor Berkala Ilmiah Indonesia [Internet]. Bogor: Himpunan Editor Berkala Ilmiah Indonesia [cited 2018 Aug 6]. Available from: http://indonesianeditor.org/

13. Korean Council of Science Editors [Internet]. Seoul: Korean Council of Science Editors [cited 2018 Aug 6]. Available from: https://www.kcse.org/

14. Korean Association of Medical Journal Editors. KoreaMed [Internet]. Seoul: Korean Association of Medical Journal Editors [cited 2018 Aug 6]. Available from: http://www.koreamed.org

15. Sinta Indonesia. Science and Technology Index Indonesia [Internet]. [place unknown]: Ministry of Research, Technology, and Higher Education of Republic of Indonesia [cited 2018 Aug 6]. Available from: http://sinta2.ristekdikti.go.id/

16. Lukman L, Rianto Y, Hakim SA, Nadhiroh IM, Hidayat DS. Citation performance of Indonesian scholarly journals indexed in Scopus from Scopus and Google Scholar. Sci Ed 2018;5:53-8. https://doi.org/10.6087/kcse.119

17. Dimyati M. Strengthening research and development through national journal in Indonesia. Paper presented at: Joint Convention of the Asia Pacific Association of Medical Journal Editors and the 5th Asian Science Editors Conference \& Workshop; 2018 Jul 18-19; Bogor, Indonesia.

18. Janairo JI. Reviving a scientific journal: challenges and strategies. Sci Ed 2018;5:59-61. https://doi.org/10.6087/kcse.120

19. Jue DM. Life as an editor: developing a domestic journal to an international journal. Sci Ed 2018;5:70-2. https://doi. org/10.6087/kcse. 123 